\title{
Labour Market Dynamics and the Development of the ICT Cluster in the Stockholm Region
}

Mats Lundmark

Dominic Power 


\section{Labour Market Dynamics and the Development of the ICT Cluster in the Stockholm Region}

Mats Lundmark* and Dominic Power **

*Human Geography and Department of Social Sciences Örebro University

SE-701 82 Örebro

Sweden

mats.lundmark@sam.oru.se

** Department of Social and Economic Geography

Centre for Research on Innovation and Industrial Dynamics

Uppsala University

Box 513, S-75120 Uppsala

Sweden

Tel: +46-18-4712538 Fax: +46-18-4717418

dominic.power@kultgeog.uu.se 


\section{"Labour Market Dynamics and the Development of the ICT Cluster in the Stockholm Region.”}

\section{Introduction}

Despite the fact that in the knowledge economy successful clusters depend upon their ability to attract and retain skilled and innovative workers there has been surprisingly little written about the role of labour mobility in clusters. The majority of cluster research has concentrated on the role of inter-firm linkages, venture capital, supporting institutions, sophisticated consumers, infrastructure, etc. in helping to create a dynamic local milieu supportive of innovation and knowledge creation. Whilst focusing on such topics and actors has yielded enormous amounts of fascinating results it must be complemented by an understanding of the working lives that populate these areas. This paper makes an attempt to better understand working lives and workers in clusters by looking at the issue of the extent to which the mobility of workers in an area can be seen as an important basis for the capacity of firms in clusters to grow and learn. In particular, we address the issue of how the dynamics of labour mobility links different aspects of cluster, and how labour mobility can be seen to be a key channel through which skills and knowledge are transferred between firms and in, and into, clusters.

The basic idea in this paper is that knowledge and learning most commonly develop through interactions located in the workplace. It is in the context of working life and the spaces we work in - offices, laboratories, factories, etc. - that we perhaps most often interact, see new ideas and learn new things. If this is true then the flow of people in and out of working life and in and out of particular places may be important channels and sources for knowledge and innovation. Labour mobility can take many forms: migration from one local labour market to another; movement between firms or workplaces in the same area; changing 
from one position to another within the same organisation. Whatever the exact form it takes, the move of an individual potentially also results in a transfer of embodied knowledge from one place to another in the economy.

Studying labour market mobility is nothing new and there is a long tradition within the social sciences of studying the conditions for and the effects of labour mobility. In labour market economics, mobility has primarily been analysed in the context of industrial restructuring and wage adjustments (Burgess et al. 2000). In sociology, focus has often been on career behaviour and the impact of networks on the labour market (Furåker 1985; Granovetter 1995; Thålin 2002). In geography, labour mobility has typically been directly related to the study of migration, both internationally and between regionally (Eliasson et al. 2003). However, the idea that labour mobility plays an important role in the transfer of knowledge, especially in the local and regional economy is more recent. This new interest in labour market dynamics can be traced to several research areas. It is related to a renewed interest in local and regional agglomerations in economic geography (Storper 1995; Malmberg 2002) and neoclassical economics' revived interest in models of the geographical concentration of economic activity (Krugman 1991; Fuijta et al. 1999; Krugman 2000). In economics, the renewed interest for labour mobility is linked to new growth theory and its emphasis on human capital and knowledge formation, and the localized spill over of knowledge (Fornahl et al. 2005). Lastly, it is related to the success of the cluster concept in alerting business studies and strategists to the role of places in industrial and firm competitiveness (Porter 1990; Sölvell et al. 1991).

In this paper we outline some of the theory and findings that support the idea that labour mobility is crucial to clusters. After this we attempt to demonstrate our point by using the example of labour market mobility relations in one of the most prominent industrial clusters in Sweden: the Stockholm information and communication technology (ICT) cluster. 
To do this we use a unique data set that allows one to trace the course of every individual in the Swedish labour market in the period 1990-2000. In particular, we focus on a segment of highly educated/highly paid workers in the Stockholm labour market and analyse their mobility and careers in relation to rapid rise of the Stockholm ICT cluster. The analysis is guided by the following questions: Was the ICT cluster in the Stockholm region characterized by a higher level of mobility, compared to other parts of the region's economy? To what extent was labour mobility in the ICT cluster sensitive to different phases of the business cycle? Was mobility between the different parts of the ICT cluster higher than between the cluster and the rest of the economy? The basic idea tested in the empirical part of this paper, then, is idea that one of the features of an internationally competitive and knowledge driven industrial cluster is a dynamic and flexible labour market.

\section{Labour mobility, local knowledge, and clusters}

High degrees of labour mobility can be considered to be desirable for many reasons. Mobility helps in processes of structural transformation and adjustment: for instance, between declining industrial sectors and expanding ones. In this sense, labour mobility, both within and between labour markets, is basically a matching process where resources and competences continuously are reorganized. This matching process most often takes place within the framework of increasingly segmented labour markets (Martin and Morrison 2003). These sub markets are to a large degree separated, in the sense that mobility is between them is substantially lower that within them. The emergence of more segmented labour markets is in many countries part of a long term transformation into information and knowledge based economies, where specialist competences become more important. 
Mobility is also important for companies' supplies of competences and their adjustment to technological development and new demand. The idea that local labour markets are important for the formation and duration of industrial agglomerations has a long history. Marshall posits it as one of the three main reasons for the development of industrial districts (Marshall 1920), and it is an integral part of Weber's treatment of agglomeration forces in his theory of location (Weber [1909]1957). It is also discussed as an important building block in modern theories cluster competitiveness (Porter 1998; Malmberg 2002). Common to such theories is the idea that the local supply of skilled and specialized labour is one of the preconditions for the specialization and dynamism that clusters/agglomerations are defined by.

A more recent approach to the importance of local labour markets is based on the observation that physical proximity between firms, and other relevant institutions (like universities, R\&D units, etc), enhances the flow of labour between local economic agents and that seems to be an important source of knowledge spillovers. Indeed it is likely that labour mobility, especially if it is local, will speed up the process of knowledge dissemination between firms and institutions, and thereby enhance innovation, learning and upgrading in local areas. Fosfuri, et al. find that technological spillovers from foreign direct investment arise when a local firm later hires workers trained by a multinational firm (Fosfuri et al. 2001). This is of course of particular importance in the case of highly educated knowledge workers (researchers, specialists, engineers, programmers, etc.) moving between different employers or between workplaces in the local economy (Song et al. 2003). As already mentioned, this mechanism for knowledge creation and spillover has been relatively understudied. Breschi and Malerba point to the need to develop this line of ideas further: 
“Among the critical conditions for sparking off the growth of a new cluster, the availability of a highly skilled labour force and of university-trained human capital has been identified as one of the most important factors. If the existence of a pool of skilled workers is a key ingredient for successful clusters, the localized mobility of people (either among firms or from existing firms, universities and public research centres to new firms) is equally relevant. The mobility of skilled workers represents, in fact, the crucial source of new firm formation as well as the main mechanism through which technical and market knowledge flows locally. These remarks suggest, therefore, that the working of regional labour markets (and more specifically, the labour markets for technical, managerial and academic employees) is a very promising area, which deserves more careful study, both with reference to nascent and to established clusters. (Breschi and Malerba 2001) p. 821)

Knowledge can, of course, come in many forms and for firms and local competitiveness it seems that tacit knowledge is of particular importance (Feldman 2000; Gertler 2003). Tacit knowledge is by nature impossible to codify and easily communicate, and thus tends to be carried or embodied in the individual. Since tacit knowledge is difficult to articulate and often highly subjective, it is transferred most effectively through regular face-to-face interaction. Labour mobility is, of course, not the only mechanism through which tacit knowledge spills over between firms and organizations: other important channels are regular business contacts, new start-ups, networking between firms, multiple affiliations, joint projects, etc. However, being an employee is, usually, a far deeper connection and relation to a firm than irregular meetings. Moreover new employees moving into firms opens the possibility not just for the spread of tacit knowledge but, through the immediacy of face-to-face interaction, the 
possibility that new combinations of knowledge are created at the level of the workplace or the firm (Basant 2002).

Labour mobility is, in theory, not just about new resources and knowledges coming into the firm but also about creating and cementing links between firms, workplaces, and institutions: links that are developed in the workplace as well as in other interactive arenas. Indeed labour mobility often links to a wider sense of mobility and interaction that characterises those that work in successful clusters. As Saxenian notes of the working culture in Silicon Valley:

They move from established firms to start-ups (or vice versa) and even to market research or consulting firms, and from consulting firms back into start-ups. And they continue to meet at trade shows, industry conferences, and the scores of seminars, talks, and social activities organized by local business organizations and trade associations. [...] This decentralized and fluid environment also promotes the diffusion of intangible technological capabilities and understandings. (Saxenian 1990), p.96-97)

Though people move they often stay in contact with old friends, colleagues, suppliers, clients, etc.; thereby expanding their new firm's network. In this respect flows of labour between firms and workplaces may bring new business contacts and widen the scope of potential customers, as well as increasing the possibility to identify potential partners for future collaboration. In this sense, the flow of individuals between workplaces, firms and institutions has a cluster and network building potential. Evidence suggests that this is certainly true of firms in high-technology and knowledge intensive sectors where firms' main assets are their human, reputational, and network capital: (Saxenian 1994; Angel 2000; 
Grabher 2001; Benner 2003; Lawton-Smith 2003). Of course, such interpersonal relations and connections do not just work to help cluster firms’ stock of knowledge, etc. Such connections can function as 'cluster glue' (Sölvell et al. 2003): stick people together and help them form a shared consciousness of the cluster and its parameters.

Whilst labour mobility may in the long run benefit the cluster, and the development of technologies and knowledge in general, high levels of mobility may not always be so positive for individual people and firms: mobility has its price then for individual firms (Almeida and Kogut 1999; Lawson 1999; Dahl 2002). For firms the turnover of staff does not only mean the introduction of new competences and ideas but also involves investments in training and adjustment periods that can be costly to ongoing projects and existing workplace cultures. Indeed there are possible diseconomies involved with 'hyper' or 'excessive' mobility: it can result in extra costs for younger firms; it can act as a disincentive for investment in skills upgrading; it can lead to poaching of and competition for workers that undermines inter-firm trust; it can drain away skilled workers from fledgling firms, weaker regions and weaker firms. Studies exist that suggest that staff turnover is considerably higher in larger urban areas and that this can be a problem for certain types of firms that happen to be located in such areas (Orkan 1972); this tendency has been noted to be especially true for ICT firms (Carnoy et al. 1997; Lawton-Smith and Waters 2003).

In certain cases mobility can also spread vital information to firms' competitors. When leaving for another employer, the individual brings with her not only specific competences and skills but sometimes also long-standing business relations, customers and strategic business information. If trade secrets are weakly protected by law, firms are especially vulnerable to losing valuable information when competitors hire employees. Ronde shows that it is more profitable to reduce the information sharing by giving employees different information than by giving some employees more information than others (Ronde 2001). 
Labour mobility and labour turn over is, thus, for most firms (and for public institutions) to a large extent a question of a trade off between, on the one hand, getting the benefits of bringing in new skills, competences and contacts into the firm, and on the other, of paying the price of losing skilled persons, and sometimes even losing control over firm specific know-how (Tomlinson and Miles 1999; Tomlinson 2002; Madsen et al. 2003). However, as Lewis and Yao note, employee turnover is often high in knowledge-driven industrial markets despite each firm's interest in restricting knowledge flows resulting from employee departures (Lewis and Yao 2003).

At the level of the individual mobility is also a double-edged process. On the one hand it often widens his/her career opportunities, allows them to learn new things and normally increases incomes (Cooper 2001; Dahl 2002). But mobility also has its price for the individual mover since there are economic, familial and social costs involved in moving from one place and settling in another. In the European context the high personal costs and commitments needed to move into new cultures and even language groups can be a strong disincentive to mobility. The many faces of labour mobility make processes of political and social regulation (Peck 1996; Rauhut and Falkenhall 2005) important issues for the future development and welfare of not only clusters and firms but also regions and individuals.

\section{Studying labour mobility in local areas}

Whilst there is compelling evidence for thinking that labour mobility is important learning and adaptation in clusters until very recently there have been few empirical studies focusing on this issue. In general this is probably due to the problems associated with accurately, or even approximately, tracking employment changes and mobility in clusters. This probably explains why the majority of studies have been based on only very partial data 
or on small scale qualitative studies of particular workers or firms. Such studies and techniques have yielded many enormously interesting results (Pinch and Henry 1999; Henry and Pinch 2000; Bienkowska and Hedberg 2006) but there is still also a need for statistical studies based on large and more generalizable samples. However, in recent years in Scandinavia the availability of new large scale statistical datasets that chart individuals' working lives in great detail has lead to a number of studies on the role of mobility in cluster development (Dahl 2002; Dahl and Pedersen 2003; Power and Lundmark 2004).

The rest of this paper builds on these earlier studies, in particular our own work on clusters in the Stockholm region. The results presented are based on a uniquely detailed time series dataset. This is based on official taxation and civil registration records and contains complete details on everything from education to career changes to income levels for every individual employee active in the Stockholm 'local labour market' (LLM; as defined by (Statistics Sweden 2003). The detail of the individual records and the complete nature of the data set mean that it offers a unique possibility to examine, on a large scale, the micro dynamics of individuals in the labour market and in clusters. The data contains detailed information on every individual in working age (16 years and older) in the Stockholm labour market region. In the databases used in this study there is detailed information for each individual's labour market status, educational attainment, sex, age, family situation, country of birth, income, etc. The data also contains information on workplaces and firms in the Stockholm region. In total more than 1.1 million individuals are recorded in the dataset.

For the study labour mobility one important feature of this dataset is that each individual can be traced over time in the database. The study period covers the entire 1990s, but the data are divided into two separate, but basically similar, databases. The first database (GEOMETRO) covers the first half of 1990s and the second half is covered by another database (PLACE). A second important feature of the dataset is that every individual is linked 
to a localized workplace. The workplaces are in turn linked to their economic or juridical unit (the firm or the organization the workplace is owned by) and their activities coded into the Swedish Standard for Industrial Classification system (Svensk näringsgrensindelning, SNI 92); which corresponds to the European NACE classification system. These features make it possible to identify the ICT cluster in the Stockholm region and at the same time keep track of the movement of employees between employers from one point in time to the next.

Our definition of the ICT sector in this paper is very close to the OECD's definition (OECD (Organisation for Economic Co-operation and Development) 2002; OECD (Organisation for Economic Co-operation and Development) 2003). This definition is based on 19 SIC codes (at the 5-digit level). In studying a cluster it is also important to make some sort of distinction between different activity areas and foci within the cluster. In the results presented below, the ICT sector is divided into three different sub sectors: manufacture of ICT products; wholesale and distribution of ICT products; and ICT services (see Table 1).

As already mentioned the study presented here focuses on the labour mobility of highly educated and skilled workers. The idea behind this narrowing of our focus is that it is likely this kind of labour contributes the most to innovative activity and competitiveness in a knowledge driven localized cluster. We decided upon the use of a double criterion to define this group: educational attainment and income. Two criteria were used because, especially in the case of the ICT cluster, formal education is not the only valid indicator of knowledge and skills. High pay is a relatively good indicator that a person is considered particularly valuable/successful in their work (Dahl and Pedersen 2003). In operational terms this group is defined as those having more than three years of third-level/university education or the top 30 per cent best paid employees. The latter criteria also mean that self employed persons are not included in the empirical analysis (apart from the overall picture given in Tables 1 and 2). 


\section{The ICT cluster in Stockholm}

Throughout the 1990s the ICT sector in Stockholm grew rapidly. Centred on the high profile Kista Science Park and a number of large Swedish and foreign firms the ICT thrived. Despite difficulties in measuring the exact parameters of a cluster and even with the usefulness of the concept itself (Malmberg and Maskell 2002; Martin and Sunley 2003), by the late 1990s both outside observers and the firms themselves were almost entirely convinced that a strong ICT cluster existed in the Stockholm metropolitan region. By the late 1990s the image of a rapidly growing and highly innovative and dynamic ICT cluster in the Stockholm area had been established. By 2000 Wired magazine, the standard bearer for 1990s high-tech, ranked Stockholm and Kista Science Park after Silicon Valley as the second most dynamic high-tech region in the world. In the same year Newsweek proclaimed Stockholm to be 'Europe’s Internet Capital'.

In other words it became clear to many people that Stockholm was not merely home to a large number of disassociated ICT firms but to a set of complementary and interlinked firms and institutions that had developed a shared consciousness and identity as an industrial cluster and system. This development was fuelled by many different factors and inputs (both public and private) and the generally high levels of success enjoyed by the firms in the cluster, until the bubble eventually started deflating at the very end of the 1990s, had a range of powerful effects on the city and region. Not least of these was an influx of people into the city and the growing sector, and an increasing dependence on ICT as the core driver of Stockholm's labour market and industrial profile (Birkinshaw 1998; Birkinshaw 2000).

In Table 1 the general parameters of this booming cluster story can clearly be seen. The year 2000 was in many ways the peak of a sustained period of fast growth. The cluster's story is in stark contrast to the economic picture in the rest of the economy during the same 
period. In particular, the first half of 1990s was characterized by one of the worst economic recession in Sweden since the 1930s. Between 1990 and 1995 the number of employees on the Stockholm labour market fell by 9.5 per cent giving rise to high unemployment. After 1995 the economy recovered considerably, and employment increased by 14 per cent 199500. Against this background the ICT cluster continued to grow steadily and buck the region's predominant trends; with employment reaching 61,000 in 1995 and 89,000 in 2000.

Table 1. Employment in different parts of the Stockholm ICT cluster 1990, 1995 and 2000.

\begin{tabular}{|c|c|c|c|c|c|}
\hline Industry (SNI code) & $\begin{array}{r}\text { Empl. } \\
1990 \\
\end{array}$ & $\begin{array}{r}\text { Empl. } \\
1995 \\
\end{array}$ & $\begin{array}{r}\text { Empl. } \\
2000 \\
\end{array}$ & $\begin{array}{r}\text { Change } \\
90-95(\%)\end{array}$ & $\begin{array}{r}\text { Change } \\
95-00(\%) \\
\end{array}$ \\
\hline Manufacture of office machinery and computers (30020) & 4890 & 1674 & 615 & $-65,8$ & $-63,3$ \\
\hline Manufacture of electricity distribution and control apparatus (31200) & 892 & 447 & 843 & $-49,9$ & 88,6 \\
\hline Manufacture of other electrical equipment (31620) & 1254 & 599 & 582 & $-52,2$ & $-2,8$ \\
\hline Manufacture of electronic components (32100) & 1018 & 2688 & 3237 & 164,0 & 20,4 \\
\hline Man. of TV/radio transmitters, line telephony and telegraphy (32200) & 12387 & 14000 & 13785 & 13,0 & $-1,5$ \\
\hline Man. of TV/radio receivers, sound/video apparatus, etc. (32300) & 645 & 1257 & 1798 & 94,9 & 43,0 \\
\hline Man. of appliances for measuring, checking, testing, etc. (33200) & 2943 & 3323 & 2534 & 12,9 & $-23,7$ \\
\hline Man. of industrial process control equipment (33300) & 812 & 118 & 336 & $-85,5$ & 184,7 \\
\hline ICT manufacturing subtotal & 24841 & 24106 & 23730 & $-3,0$ & $-1,6$ \\
\hline Wholesale of electrical equipment (51434) & 2417 & 2153 & 2340 & $-10,9$ & 8,7 \\
\hline Wholesale of office machinery and equipment (51640) & 12120 & 11351 & 13428 & $-6,3$ & 18,3 \\
\hline Wholesale of computerized materials handling equipment (51652) & 779 & 233 & 496 & $-70,1$ & 112,9 \\
\hline Wholesale of telecom. equip. and electrical components (51653) & 3580 & 4076 & 5246 & 13,9 & 28,7 \\
\hline ICT trade subtotal & 18896 & 17813 & 21510 & $-5,7$ & 20,8 \\
\hline Hardware consultancy (72100) & 70 & 249 & 604 & 255,7 & 142,6 \\
\hline Software consultancy (72201 & 10138 & 12411 & 31648 & 22,4 & 155,0 \\
\hline Software supply (72202) & 1092 & 2133 & 7214 & 95,3 & 238,2 \\
\hline Data processing (72300) & 2446 & 2843 & 2662 & 16,2 & $-6,4$ \\
\hline Data base activities (72400) & 508 & 550 & 755 & 8,3 & 37,3 \\
\hline Maintenance of office accounting and computing machinery (72500) & 474 & 634 & 544 & 33,8 & $-14,2$ \\
\hline Other computer related activities (72600) & 569 & 280 & 620 & $-50,8$ & 121,4 \\
\hline ICT service subtotal & 15297 & 19100 & 44047 & 24,9 & 130,6 \\
\hline ICT total & 59034 & 61019 & 89287 & 3,4 & 46,3 \\
\hline Universities, R \& D $(803,73)$ & 15510 & 16702 & 19174 & 7,7 & 14,8 \\
\hline Rest of the labour market & 874175 & 780675 & 872081 & $-10,7$ & 11,7 \\
\hline Total Stockholm labour market & 948719 & 858396 & 980542 & $-9,5$ & 14,2 \\
\hline
\end{tabular}

Source: Databases PLACE and GEOMETRO/Statistics Sweden. 
As can be seen from Table 1 the cluster, at least in the definition we use, consists of a wide variety of ICT activities. Within these figures we can find signs of the adjustment processes and changes happening within the cluster itself. Under the period the cluster became increasingly dominated by ICT services. The core element of the cluster has always been the telecommunications category - within which much of the Swedish global giant Ericsson is contained (SNI-92 code 32200). Between 1990 and 2000 this manufacturing core shrank from $21 \%$ of the cluster's workforce to $15 \%$. Indeed the manufacturing focus of the cluster in general shrank both as proportion of the cluster's activities and in absolute terms whilst ICT trade and, in particular, ICT services expanded rapidly. As the cluster developed it became more and more diverse in its product offerings and new entrants flooded into ICT services and areas such as software consulting. As we shall see later this transformation process was consistently backed up by corresponding labour flows.

It is not only, however, in the area of employment growth that the cluster proved to be at odds with the rest of the regional economy. In the period it had a labour force that was predominantly male, younger, better educated, and higher earning than the rest of the LLM (see Table 2). When we look only at those with high education and/or high income (50\% of ICT employees, 30\% of rest of LLM's employees) we can find that these differences are further accentuated. 
Table 2. Labour characteristics of the ICT cluster in the Stockholm region in 2000.

\begin{tabular}{lrrrr}
\hline & $\begin{array}{l}\text { ICT } \\
\text { Manufacturing }\end{array}$ & $\begin{array}{l}\text { ICT } \\
\text { Trade }\end{array}$ & $\begin{array}{l}\text { ICT } \\
\text { Service }\end{array}$ & $\begin{array}{l}\text { Total } \\
\text { LLM }\end{array}$ \\
Sex & $70.1 \%$ & $70.3 \%$ & $71.1 \%$ & $51.9 \%$ \\
Men & $29.9 \%$ & $29.7 \%$ & $28.9 \%$ & $48.1 \%$ \\
Women & & & & \\
Age & $42.8 \%$ & $49.1 \%$ & $55.7 \%$ & $39.2 \%$ \\
$0-35$ & $47.0 \%$ & $42.9 \%$ & $39.4 \%$ & $46.9 \%$ \\
$36-55$ & $10.2 \%$ & $8.0 \%$ & $4.9 \%$ & $13.9 \%$ \\
$56-\mathrm{w}$ & & & & \\
Education* & $25.3 \%$ & $32.2 \%$ & $15.8 \%$ & $39.3 \%$ \\
Low & $39.9 \%$ & $50.4 \%$ & $45.7 \%$ & $37.0 \%$ \\
Medium & $33.2 \%$ & $16.5 \%$ & $37.8 \%$ & $22.8 \%$ \\
High & & & & \\
Income** & 3293 & 3532 & 3698 & 2417 \\
Mean & 2894 & 2984 & 3425 & 2171 \\
Median &
\end{tabular}

* Low = elementary school (9 years) or two years senior high school; Medium = three years senior high school or two years university; High = at least three years of university education.

** Income from paid work in hundreds of SEK.

Source: PLACE/Statistics Sweden.

\section{Labour mobility in the Stockholm ICT cluster}

In this section we directly address the following three questions: Was the ICT cluster in the Stockholm region characterized by a higher level of mobility, compared to other parts of the region's economy? To what extent was labour mobility in the ICT cluster sensitive to different phases of the business cycle? Was mobility between the different parts of the ICT cluster higher than between the cluster and the rest of the economy?

Turning to the first of these questions we find that the simple answer to the question is: yes, the cluster had comparatively higher rates of mobility than the rest of the local economy. In Table 3 the likelihood of changing employer is estimated for the sub sectors of the ICT cluster and for other branches of manufacturing, trade and business services in the rest of the economy in two time periods (the recessionary early1990s and boom period of 1995-2000). These are then compared to mobility among the rest of the employees on the Stockholm labour market. The calculations have been limited to persons with high education 
and/or high income, and each model only includes persons being active on the Stockholm labour market in both periods. In the models we control for age and sex.

Table 3. Estimation of likelihood of changing employer 1990-1995, and 1995-2000.* Logistic regressions. (Standard errors in brackets).

\begin{tabular}{lrr}
\hline & $1990-19995$ & $1995-2000$ \\
\hline ICT Manufacturing & $.736(.022)$ & $.908(.021)$ \\
Other Manufacturing & $.377(.013)$ & $.290(.014)$ \\
ICT Trade & $.457(.023)$ & $.822(.024)$ \\
Other Trade & $.106(.014)$ & $.277(.015)$ \\
ICT Service & $.846(.024)$ & $1.179(.022)$ \\
Other Business service & $.321(.011)$ & $.511(.011)$ \\
Rest of the labour market & 0 & 0 \\
& & \\
$20-35$ years & $.830(.014)$ & $1.280(.016)$ \\
$36-55$ years & $.308(.011)$ & $.517(.010)$ \\
$56-$ w years & 0 & 0 \\
& & \\
Sex, Male=1 & $.402(.009)$ & $.093(.009)$ \\
Constant & & \\
\hline
\end{tabular}

Source: Databases PLACE and GEOMETRO/Statistics Sweden.

*Employed persons with a university education and/or high income. Only employees active on the Stockholm labour market 1990, 1995 and 2000 are included in the analysis.

What is clear from Table 3 is a surprisingly uniform and stable pattern. In both periods the likelihood of having changed employer is significantly higher if you belonged to the ICT cluster than if you worked in other manufacturing, trade or service areas of the Stockholm economy. However, in the economic upturn period of 1995-2000 the difference between cluster members and other employees became more pronounced. In line with the growing emphasis on the service sector in the cluster mobility was highest in services; followed by manufacturing and trade.

The regressions in Table 3 also highlight differences between age groups: mobility decreased with age. This is perhaps not startling as diminished mobility with age has been found in many other studies of labour mobility, regardless of what section of the labour market focused (Jansson 1997). When we turn to men and women we find that the differences are negligible in the second period but fairly strong in the first period. In other words, during 
the recession years male mobility was significantly higher but as soon as the situation on the labour market improved during the difference seemed to disappear.

The results of the regression analysis point in the direction of higher rates of mobility for employees within the ICT cluster, independent of individual characteristics like age and sex. Furthermore this conclusion seems to hold true regardless of up or downturns in the economy and on the labour market as a whole. Labour mobility in the ICT cluster is thus relatively immune to different phases in the general economy's business cycle. However, as we see below the particular character of mobility within and into the cluster is highly sensitive to different phases in the business cycle and adjustment processes the cluster itself is undergoing.

We now turn to the question of mobility within the ICT cluster by concentrating on labour mobility between the different sectors of the ICT cluster between 1995-2000. In Figure 1 the flows of labour between the constituent parts of the ICT cluster have been calculated by relating the absolute numbers of movers to the total amount of labour in each sector in 1995. The flows are thus expressed as percentages, and the magnitude of the flows are illustrated by the thickness of the arrows. In the first three parts of the figure (a-c) we highlight each of the three sub sectors and its exchange of labour with, not only the other ICT sectors, but also with the university and $\mathrm{R} \& \mathrm{D}$ sector, and the rest of the Stockholm local labour market. In the fourth part of the figure (d) the flows in both directions are summarized, showing the extent of the bonds made by labour mobility between sectors. 
Figure 1 a-d. Flows of labour between the different sectors of the ICT cluster in the Stockholm region 1995-2000. Figures are for employed persons with a university education and/or high income who were active on the Stockholm labour market both in 1995 and 2000.
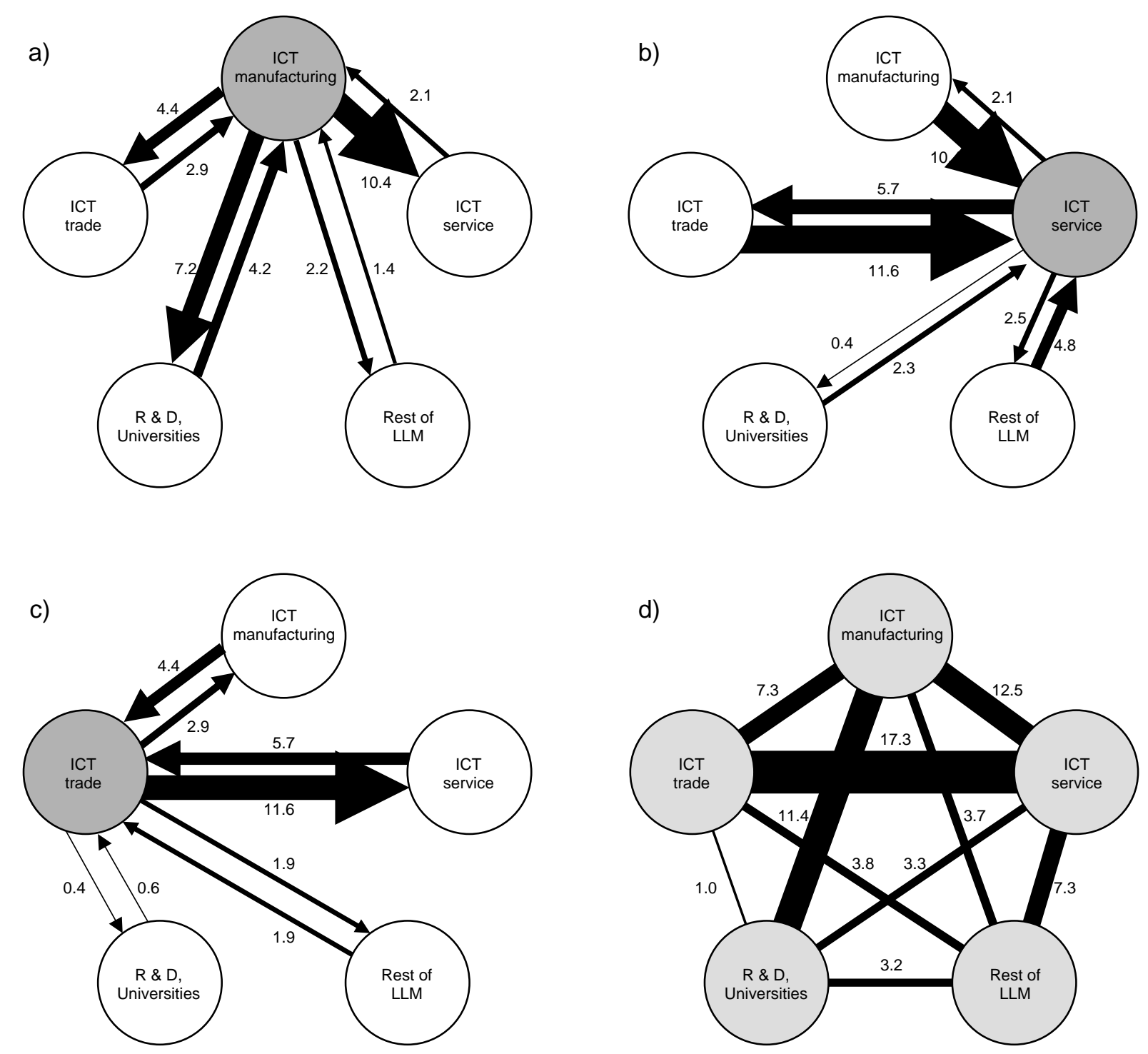

As could be seen in Table 1, employment in ICT manufacturing decreased by 1.6 per cent during the second half of 1990s. This is also reflected in Figure 1 where outflows of workers to other sectors were significantly higher than inflows. The largest flow in numbers (rather than percentages) in this period was from ICT manufacturing to the ICT service sector. At the same time there were substantial two way flows between ICT manufacturing and universities/R\&D institutions; flows that were more pronounced than in the 1990-95 period. Whilst many of the large ICT manufacturing firms in Stockholm have 
traditionally been strongly associated with the research world (especially in the case of Ericsson and the KTH-Royal Institute of Technology), it seems that the downturn in manufacturing led to intensified interaction with the research community. This can be interpreted in a number of ways: as an attempt by firms to upgrade their skills base in order to survive; as an attempt by firms to cut costs by outsourcing $\mathrm{R} \& \mathrm{D}$; or as a route taken by workers out of a diminishing sector. The ICT service sector is, on the other hand, characterized by a net inflow of labour from all other sectors: in particular from ICT trade and from ICT manufacturing. The exchange with the University/R\&D sector is less pronounced, and in this case characterized by a net inflow. The ICT trade sector is clearly related to the other ICT sectors, with a net inflow coming in from the manufacturing sector and a net outflow into the service sector.

The overall picture in Figure 1d supports the idea of a cluster of interrelated and systemically related activities; a conclusion that also could be drawn for the period 1990-1995 (see Power \& Lundmark, 2004, p.1037). There is also an obvious net flow from the other sectors, including universities/R\&D departments and the rest of the labour market, into the rapidly growing ICT service sector. Major inflows into the growth pole of the cluster originate from the other two ICT sectors. The intensity of the mobility relations between the different parts of the ICT cluster was higher than the intensity of mobility between the cluster and the rest of the economy. These patterns give credence to the idea that there is a 'proximity of competences' between the three ICT sectors and that this in turn is a good indicator of a coherent and dynamic cluster at work.

In Figure 1, the analysis is confined to the individuals that remained on the Stockholm labour market between 1995 and 2000, showing the internal flows of labour on the local labour market. In Table 4 the analysis is extended to the inflows of persons not previously employed (coming, for example, out of education or from unemployment) or 
persons employed outside the Stockholm labour market. The ICT trade sector is close to the general picture displayed by the total labour market, but both ICT manufacturing and ICT services deviate from the general pattern.

Table 4. Inflows of labour into the ICT cluster 1995-2000.* Share of employment in 2000 (\%).

\begin{tabular}{lrrr}
\hline ICT sub sector & Not active on the labour & Employed in the & Employed outside the \\
& market in 1995 & Stockholm LM 1995 & Stockholm LM in 1995 \\
ICT Manufacturing & 12.9 & 74.4 & 12.7 \\
ICT Trade & 6.5 & 80.6 & 12.9 \\
ICT Service & 8.6 & 71.0 & 20.4 \\
Total Stockholm LM & 6.9 & 78.7 & 14.4 \\
\hline
\end{tabular}

Source: PLACE/Statistics Sweden.

*Employed persons in 2000 with a university education and/or high income.

In ICT manufacturing a larger share of those employed in 2000 recruits of persons who were not active on the labour market in 1995. Although we cannot distinguish between individuals coming directly from education or from unemployment, there is good reason to believe, given that we focused on highly educated/highly paid employees, that the majority of individuals in this category had a university degree or valuable skills. Again, this points to the particularly strong links between ICT manufacturing and the university system in the region: a symbiosis which developed over a much longer period of time, in comparison to the other 'younger sectors of the ICT cluster.

In the case of the recruitment of labour from outside the Stockholm region we can see further evidence of the magnetic effect of growing activity areas/sectors since inflows and immigration played a more significant role in ICT services. This is probably to some extent explained by the remarkable growth and exceptional demand for labour that took place in the Stockholm Internet sector towards the end of 1990s. However, as the bubble burst after 2000 the situation was reversed and it became extremely difficult for 'outsiders' who were not part of the established networks within the business to get access to new jobs (Jansson 2005), pp148-150). 


\section{Conclusions}

The results presented in this paper go some way in empirically verifying the idea that labour market mobility is significantly higher in growing clusters than in the rest of the urban economy. The evidence from the Stockholm ICT cluster clearly shows that high rates of mobility into growing clusters occur and that the cluster was characterized by higher levels of mobility than other parts of the region's economy. In addition, it can be seen that labour mobility within the cluster followed the developmental path, or life cycle, of the cluster. In the Stockholm case intra-cluster mobility was focused on supplying the growing ICT services element of the cluster. This backs up the idea that mobility within clusters is heavily involved in structural adjustment and transformation processes. The fact that the most highly educated and earning individuals had the highest rates of mobility in the cluster and that their mobility was much more oriented towards flows into the growth sector of the cluster supports the idea that key knowledge workers are at the forefront of such transformations. This gives some support to the idea that labour mobility is a key channel for knowledge and skills upgrading in growth areas.

Such findings give some indication to the central role labour mobility seems to play in cluster growth and dynamics; as well as in how clusters secure new talent and embodied knowledge. It is important then that cluster research continues to investigate the role of labour market mobility in creating not just the conditions for innovation and knowledge creation but also the channels for the spread and diffusion of knowledge and innovation within clusters and firms in clusters. The findings presented in this paper suggest that labour mobility could be seen as a key marker or indicator for not only the parameters and definition of specific clusters but also for a series of dynamic transformation and 
knowledge processes that may explain the development of successful clusters. Our hope is that cluster research of all types - whether it is focused on large scale datasets, qualitative studies, or cluster theory - will continue to explore how working lives, careers, and labour contribute to the development of clusters.

\section{References}

Almeida, P. and B. Kogut (1999) "Localization of Knowledge and the Mobility of Engineers in Regional Networks." Management Science 45(7), 905-917.

Angel, D. (2000) High-Technology Agglomeration and the Labor Market: the Case of Silicon Valley. Understanding Silicon Valley. The Anatomy of an Entrepreneurial Region. M. Kenney. Stanford, Stanford University Press.

Basant, R. (2002) Knowledge flows and industrial clusters. An analytical review of literature. Mimeo. Ahmedabad, India, Indian Managemant.

Benner, C. (2003) "Learning communities in a learning region: the soft infrastructure of cross-firm learning networks in Silicon Valley." Environment and Planning A 35(10), 1809-1830.

Bienkowska, D. and C. Hedberg (2006) Arbetskraftens rörlighet och kunskapsspridning i kluster: Exemplet IT- och telekomföretag i Kista. Stockholm, Arbetslivsinstitutet.

Birkinshaw, J. (1998) The Information Technology Cluster in Stockholm - Prospects for Development. 1998/6. Stockholm, Invest in Sweden Agency.

Birkinshaw, J. (2000) The information technology cluster in Stockholm: changes from 1997 to 2000 and prospects for continued growth. Stockholm, Invest in Sweden Agency.

Breschi, S. and F. Malerba (2001) "The Geography of Innovation and Economic Clustering: Some introductory notes." Industrial and Corporate Change 10(4).

Burgess, S., J. Lane and D. Stevens (2000) "Job Flows, Worker Flows, and Churning." Journal of Labor Economics 18(3), 473-502.

Carnoy, M., M. Castells and C. Benner (1997) "Labour market and employment practices in the age of flexibility: a case study of Silicon Valley." International Labour Review 136(1), 27-48.

Cooper, D. (2001) "Innovation and reciprocal externalities: information transmission via job mobility." Journal of Economic Behavior and Organization 45(4), 403-425.

Dahl, M. (2002) Embedded knowledge flows through labor mobility in regional clusters in Denmark. DRUID's New Economy Conference, Copenhagen.

Dahl, M. and C. Pedersen (2003) Knowledge Flows through Informal Contacts in Industrial Clusters: Myths or Realities? DRUID Working Paper 03-01. Copenhagen, DRUID.

Eliasson, K., U. Lindgren and O. Westerlund (2003) "Geographical Labour Mobility: Migration or Commuting?" Regional Studies(37), 8.

Feldman, M. (2000) Location and innovation: the new economic geography of innovation, spillovers, and agglomeration. The Oxford Handbook of Economic Geography. G. Clark, M. Feldman and M. Gertler. Oxford, Oxford University Press.

Fornahl, D., C. Zellner and D. Audretsch, Eds. (2005) The Role of Labour Mobility and Informal Networks for Knowledge Transfer. New York, Springer. 
Fosfuri, A., M. Motta and T. Ronde (2001) "Foreign direct investment and spillovers through workers' mobility." Journal of International Economics 51(1), 204-222.

Fuijta, M., P. Krugman and A. Venables (1999) The Spatial Economy: cities, regions, and international trade. Cambridge, Mass., The MIT Press.

Furåker, B. (1985) Stat och arbetsmarknad. Studier i svensk rörlighetspolitik. Lund, Arkiv.

Gertler, M. (2003) "Tacit knowledge and the economic geography of context, or The undefinable tacitness of being (there)." Journal of Economic Geography 3, 75-100.

Grabher, G. (2001) "Ecologies of creativity: the Village, the Group, and the heterarchic organisation of the British advertising industry." Environment and Planning A 33(2), 351-374.

Granovetter, M. (1995) Getting a Job. A Study of Contacts and Careers. 2nd edition. Chicago, Chicago University Press.

Henry, N. and S. Pinch (2000) (The) Industrial agglomeration (of Motor Sport Valley): A Knowledge, Space, Economy Approach. Knowledge, Space, Economy. J. Bryson, Daniels, P., Henry, N. and Pollard J. London, Routledge.

Jansson, F. (1997) "Åldersstrukturens betydelse för arbetskraftens rörlighet." Arbetsmarknad \& Arbetsliv 3(4).

Jansson, J. (2005) The Internet Industry in Central Stockholm. A study of agglomeration economies, social network relations, and information flows. Geografiska regionstudier 63. Uppsala, Uppsala University.

Krugman, P. (1991) Geography and Trade. Cambridge, MA, MIT Press.

Krugman, P. (2000) Where in the World is the 'New Economic Geography'? The Oxford Handbook of Economic Geography. G. Clark, M. Feldman and M. Gertler. Oxford, Oxford University Press.

Lawson, C. (1999) "Towards a competence theory of the region." Cambridge Journal of Economics 23, 151-166.

Lawton-Smith, H. (2003) "Local innovation assemblages and institutional capacity in local high-tech economic development: The case of Oxfordshire." Urban Studies 40(7), 1353-1369.

Lawton-Smith, H. and R. Waters (2003) Rates of turnover in high-tech agglomerations: knowledge transfer in Oxfordshire and Cambridgeshire. Association of American Geographers Annual Meeting, New Orleans.

Lewis, T. and D. Yao. (2003) "Innovation, knowledge flow, and worker mobility." Retrieved 5 March, 2003, from rider.wharton.upenn.edu/ yao/SVsubmitjune03.pdf.

Madsen, T., E. Mosakowski and S. Zaheer (2003) "Knowledge retention and personnel mobility: The nondisruptive effects of inflows of experience." Organization Science 14(2), 173-191.

Malmberg, A. (2002) Klusterdynamik och regional näringslivsutveckling begreppsdiskussion och forskningsöversikt. Stockholm, ITPS (Institutet för Tillväxtpolitiska Studier).

Malmberg, A. and P. Maskell (2002) "The elusive concept of localization economies: towards a knowledge-based theory of spatial clustering." Environment and Planning A 34, 429-449.

Marshall, A. (1920) Principles of Economics. London, Macmillan.

Martin, R. and P. Morrison, Eds. (2003) Geographies of Labour Market Inequality. Regional Development and Public Policy Series. London and New York, Routledge.

Martin, R. and P. Sunley (2003) "Deconstructing clusters: chaotic concept or policy panacea?" Journal of Economic Geography 3(1), 5-35.

OECD (Organisation for Economic Co-operation and Development) (2002) Measuring the Information Economy 2002. Paris, OECD. 
OECD (Organisation for Economic Co-operation and Development) (2003) A Proposed Classification of ICT Goods. Paris, OECD Working Party on Indicators for the Information Society.

Orkan, L. (1972) Regionala variationer i företagens personalomsättning. Umeå, Ekonomiska institutionen, Avdelning för företagsekonomi, Umeå universitet.

Peck, J. (1996) Work-Place: the Social Regulation of labor markets. New York, Guilford.

Pinch, S. and N. Henry (1999) "Discursive aspects of technological innovation: the case of the British motor-sport industry." Environment \& Planning A 31, 665-682.

Porter, M. (1990) The Competitive Advantage of Nations. New York, The Free Press.

Porter, M. (1998) "Clusters and the new economics of competition." Harvard Business Review Nov-Dec, 77-90.

Power, D. and M. Lundmark (2004) "Working through knowledge pools: labour market dynamics, the transference of knowledge and ideas, and industrial clusters." Urban Studies 41(5/6), 1025-1044.

Rauhut, D. and B. Falkenhall, Eds. (2005) Arbetsrätt, rörlighet och tillväxt. A2005:016. Stockholm, ITPS.

Ronde, T. (2001) "Trade secrets and information sharing." Journal of Economics and Management Strategy 10(3), 391-417.

Saxenian, A. (1990) "Regional Networks and the Resurgence of Silicon Valley." California Management Review 33, 89-111.

Saxenian, A. (1994) Regional Advantage: culture and competition in Silicon Valley and Route 128. Cambridge, Mass., Harvard University Press.

Song, J., P. Almeida and G. Wu (2003) "Learning-by-hiring: When is mobility more likely to facilitate interfirm knowledge transfer?" Management Science 49(4), 351-365.

Statistics Sweden (2003) Regional divisions in Sweden on 1 January 2003. Reports on Statistical Co-ordination for the Official Statistics of Sweden. Stockholm, SCB.

Storper, M. (1995) "The resurgence of regional economies, 10 years later: the region as a nexus of untraded interdependencies." European Urban and Regional Studies 2, 191 221.

Sölvell, Ö., G. Lindqvist and C. Ketels (2003) The Cluster Initiative Greenbook, Available at http://www.ivorytower.se/greenbook/general.html.

Sölvell, Ö., I. Zander and M. Porter (1991) Advantage Sweden. Stockholm, Norstedt.

Thålin, M. (2002) Ojämlikhet och rörlighet på arbetsmarknaden. Ekonomin i samhället ekonomsociologiska perspektiv. G. Ahrne and R. Swedberg. Lund, Studentlitteratur.

Tomlinson, M. (2002) Measuring competence and knowledge using employee surveys: evidence using the British skills survey of 1997. Discussion Paper No. 50. Manchester, Centre for Research on Innovation and Competition (CRIC), University of Manchester.

Tomlinson, M. and I. Miles (1999) The career trajectories of knowledge workers in mobilising human resources for innovation. Proceedings from the OECD workshop on science and technology markets. Paris, OECD.

Weber, A. ([1909]1957) Theory of the location of industries. 2nd Edition. Chicago, University of Chicago Press. 